\title{
Desafios e possibilidades na formação de professores - em torno da análise de relatórios de estágio
}

\section{Challenges and possibilities in teacher education - on the analysis of practicum reports}

\author{
Ana Isabel Andrade ${ }^{1}$ \\ Filomena Martins ${ }^{1}$
}

\begin{abstract}
RESUMO
Este texto analisa relatórios de estágio produzidos no quadro de um curso de mestrado profissionalizante para o $1^{\circ}$ Ciclo do Ensino Básico numa instituição de ensino superior público em Portugal (Universidade de Aveiro). Trata-se de compreender, a partir dos relatórios escritos e defendidos por futuras professoras, as potencialidades de formação de um trabalho pedagógico-didático que elege a diversidade linguística como objeto de intervenção. Analisa-se o conteúdo do discurso de professoras em formação inicial, recolhido num dispositivo de ação, investigação e formação, para compreensão das potencialidades de construção de conhecimento profissional que os espaços de redação dos relatórios de estágio sobre as práticas de educação para a diversidade abrem, identificando desafios e possibilidades que se colocam atualmente à formação inicial de professores.

Palavras-chave: relatório de estágio; formação de professores; conhecimento profissional; prática educativa; diversidade linguística.
\end{abstract}

\footnotetext{
ABSTRACT

This paper analyses teaching internship reports produced by future primary education teachers in the context of a professionalizing master course for

DOI: $10.1590 / 0104-4060.49134$

1 Universidade de Aveiro, Departamento de Educação e Psicologia e Centro de Investigação Didática e Tecnologia na Formação de Formadores. Aveiro, Portugal. Campus de Santiago, 3830-193.E-mails: aiandrade@ua.pte fmartins@ua.pt
} 
the $1^{\text {st }}$ Cycle of Basic Education in a Portuguese public higher education institution (University of Aveiro). The aim is to understand, on the basis of the reports written and discussed by the future teachers, the training potential of a pedagogical-didactic work that elects linguistic diversity as an intervention object. It analyses the discourse of teachers in initial training, collected under a framework of action, research and training, whose aim is the writing of the supervised teaching practice report, with a view to understand the professional knowledge construction potential that writing spaces on education practices for diversity offer, identifying challenges and possibilities that are currently posed to the initial training of teachers.

Keywords: training report; teacher education; professional knowledge; educational practice; linguistic diversity.

\section{Introdução}

Analisam-se neste texto os relatórios de estágio produzidos por futuras professoras de um curso de mestrado profissionalizante para o $1^{\circ}$ Ciclo do Ensino Básico (CEB) de uma instituição de ensino superior público em Portugal (Universidade de Aveiro), quando a diversidade linguística é objeto de estudo e de intervenção educativa no âmbito da formação. O nosso objetivo é refletir sobre as possibilidades formativas que esses relatórios indiciam, no sentido de permitirem identificar outros modos de acompanhar a sua produção. Entendem-se neste quadro os relatórios de estágio, a defender publicamente, como momentos de formação, onde a construção de conhecimento profissional se torna a principal finalidade. O processo de escrita do relatório de estágio concebe-se como um tempo de construção de conhecimento profissional, onde os saberes teóricos e práticos, adquiridos pela leitura de textos e/ou escuta de especialistas, bem como pela experienciação de situações educativas concretas, são restituídos num processo de comunicação do percurso de formação.

No quadro da Reforma de Bolonha em Portugal, os mestrados profissionalizantes para o ensino surgem enquadrados num primeiro momento pelo Decreto-Lei 43/2007 e atualmente pelo Decreto-Lei 79/2014, seguindo-se a um $1^{\circ}$ ciclo de formação de três anos, sendo o $2^{\circ}$ ciclo de formação (mestrado) aquele que confere habilitação profissional para o exercício da atividade docente após a defesa pública de um relatório de estágio. Analisam-se, neste texto, relatórios de estágio na área da educação para a diversidade linguística, escritos por futuras professoras do $1^{\circ}$ CEB e defendidos entre 2012 e 2015 . A escrita destes relatórios entende-se como um processo de reflexão constitutivo da 
construção de conhecimento profissional, procurando-se compreender percursos realizados e possibilidades de desenvolvimento (CRINON; GUIGE, 2006), em torno de um discurso que elege a diversidade linguística como espaço gerador e mobilizador de aprendizagens. Trata-se de analisar os objetos que as alunas futuras professoras colocam nos seus escritos e que povoam o seu percurso de aprendizagem profissional, comunicando-o a outros, no sentido da sua aceitação como (futuras) professoras capazes de responderem aos desafios de escolas cada vez mais diversas e complexas. (TOWSEND, 2011).

Para tal, apresentamos, num primeiro ponto, algumas ideias-chave que sustentam o programa de formação que desenvolvemos, e justificamos, num segundo ponto, a importância de abordar a área da diversidade linguística nos quatro primeiros anos de escolaridade $\left(1^{\circ} \mathrm{CEB}\right)$, para, em seguida, apresentarmos a metodologia de formação e de análise dos relatórios que essa formação permitiu escrever, dando voz às futuras professoras no sentido de podermos melhorar a formação proposta.

\section{Formação de professores e construção de conhecimento profissional}

A habilitação profissional para a docência em Portugal, como referido na introdução deste texto, adquire-se com a conclusão de um curso de mestrado que exige a defesa pública de um relatório de estágio desenvolvido em contexto educativo. Mas o que possibilita em termos formativos a redação do relatório? $\mathrm{O}$ que nos dizem os relatórios sobre o conhecimento profissional construído e, consequentemente, sobre a formação proposta e vivenciada?

Aceite a ideia de que a exigência da profissão se adequa a uma maior exigência académica, o que se traduz na passagem consensual de uma formação de licenciatura para uma formação de mestrado, parece não ser consensual a forma de conceber e pôr em prática currículos que permitam aos estudantes, futuros professores, construírem conhecimento profissional docente. Neste sentido, a formação de professores tem gerado um considerável debate em contextos académicos e de decisão política, sendo que não encontramos estudos que sigam os professores durante o período da sua formação inicial e analisem o contributo de diferentes percursos e áreas para a construção de conhecimento profissional adequado às novas exigências educativas. (ver CLARKE; LODGE; SHEVLIN, 2012; FLORES, 2010, 2011; VIEIRA; SILVA; ALMEIDA, 2014).

Apesar da diversidade de perspetivas sobre a organização da formação inicial de professores para permitir a construção de conhecimento profissional 
docente, a desenvolver ao longo da vida, julgamos que existem pressupostos partilhados que remetem para um profissional reflexivo, capaz de questionar as suas teorias e práticas e, por conseguinte, capaz de se responsabilizar pelo seu próprio conhecimento. Como refere António Nóvoa (2009), a comunidade de profissionais que estuda a formação de professores criou um consenso discursivo "[...] que tiene como base el concepto de profesor reflexivo y que ha provocado un cambio en la comprension de los professores y su formacion". (NÓVOA, 2009 , p. 50, itálico do autor), consenso esse que assenta na compreensão da complexidade e multidimensionalidade do conhecimento profissional docente, o que inclui a capacidade de questionamento e raciocínio pedagógico.

Assim, elege-se a escrita de construção de conhecimento profissional como objeto de análise, pressupondo que esse processo de escrita se constitui motor de aprendizagem docente, ocorrendo na interação entre a atividade social e a atividade (meta)cognitiva. Nesta interação, as professoras em formação mobilizam e (re)constroem saberes vários: sobre os conteúdos ou as áreas da docência; sobre a pedagogia e a didática dessas áreas; sobre o currículo, a sua organização e gestão; sobre os sujeitos a educar e os contextos de atuação; sobre as finalidades da educação e seus pressupostos histórico-filosóficos (ver AVALOS, 2009; MARCELO, 2009; SÁ-CHAVES, 2002; VIEIRA; MOREIRA, 2011).

O discurso sobre a formação de professores é marcado por ideias que incidem na formação de profissionais reflexivos e autónomos, onde se revela importante a informação, a observação, a intervenção em contexto(s) educativo(s), a colaboração e a investigação, onde a reflexão e a comunicação estão presentes no diálogo com os pares e com os supervisores ou na escrita de textos, nomeadamente diários, portefólios e relatórios sobre as práticas. Os estudos sobre a formação de professores insistem na necessidade de formar profissionais capazes de se informarem sobre o conhecimento já construído, sobre conceitos e teorias educativas, bem como sobre as áreas da docência, no sentido de saberem observar práticas educativas e mobilizar informação dirigida a problemas ou questões levantadas por essas mesmas práticas. O processo de formação de professores não dispensa a planificação, a experimentação e a avaliação de atividades educativas, bem como a colaboração com outros atores nas comunidades educativas, como oportunidades de comprometimento com a melhoria social dos contextos. (FLOYDA; COLVIN; BODUR, 2008; MORAN, 2007; SCHERFF; SINGER, 2012). Neste sentido, os estudos sobre a formação inicial de professores insistem na necessidade de desenvolver nos formandos a competência de comunicação, em processos de diálogo e partilha de experiências, redigindo escritos autobiográficos ou relatórios sobre situações de ensino/aprendizagem, onde surge a investigação como um espaço e um tempo de promoção de conhecimento profissional docente, reconhecendo que 
os formandos podem ser transformadores de si próprios e das situações em que intervêm. (MULE, 2006; PARKER, 2010).

No processo de formação inicial de professores, o relatório surge como uma espécie de narrativa da experiência, onde o autor, no sentido hermenêutico do termo, procura sentidos, tornando inteligível a ação educativa. Compreendendo-se como um dispositivo de escrita aberto e sem modelo fixo pré-determinado, o relatório de prática pedagógica supervisionada assenta na ideia de reflexão profissional em torno de um projeto de ensino, implicando um exercício de escrita de alguma complexidade, já que procura responder a exigências diversificadas - académicas, profissionais e relacionais. (CRINON; GUIGE, 2006). Este exercício de escrita constrói-se na interação orientador-formando, na interação teoria-prática, em torno de objetos pedagógico-didáticos que importa dominar e que se constituem como eixos estruturadores de percursos de formação mais ou menos conseguidos. Vejamos o que acontece com a educação para a diversidade linguística.

\section{Diversidade linguística e educação}

A educação nos primeiros anos de escolaridade pretende dotar os cidadãos de um conjunto de literacias essenciais na compreensão e transformação do mundo. Deste conjunto parecem fazer parte atividades educativas ligadas ao desenvolvimento linguístico-comunicativo, à aprendizagem da leitura e escrita, à compreensão do meio físico e social, ao desenvolvimento da numeracia, bem como ao desenvolvimento físico-motor, emocional e criativo do jovem aluno. De acordo com Lourenço (2013),

[...] a educação nos primeiros anos de escolaridade enfrenta hoje dois grandes desafios: por um lado, deverá saber lidar quotidianamente com as múltiplas diversidades (linguísticas, culturais, sociais, comportamentais, cognitivas) presentes nas escolas, de forma a garantir a equidade e o desenvolvimento pleno das potencialidades de que cada criança é portadora; por outro lado, deverá dotar as crianças de instrumentos que lhes permitam compreender e transformar um mundo marcado pela diversidade e por oportunidades em expansão. (LOURENÇO, 2013, p. 114-115). 
Assim, a diversidade, em geral, na sua multiplicidade de realizações e entendimentos, exige um enfoque educativo especial, requerendo um lugar no currículo, enquanto conteúdo a trabalhar nos primeiros anos de escolaridade, através de abordagens plurais das línguas e das culturas (CANDELIER et al., 2007), que permitam dar resposta aos desafios educativos marcados por situações de migração e mobilidade de diferente ordem (turismo, trabalho, refúgio) e pelas redes globais de comunicação, o que implica currículos de formação de professores com um entendimento mais plural e integrador das línguas na educação. Neste sentido se tem procurado introduzir a área da educação para a diversidade linguística nos currículos de formação de professores, área em que a Universidade de Aveiro se tem distinguido, como constata um estudo recente sobre a investigação na educação em línguas em Portugal. (VIEIRA; MOREIRA; PERALTA, 2014). O estudo destaca a inovação das práticas de formação através do desenvolvimento de abordagens inter/transdisciplinares das línguas e de outras áreas curriculares, o que permite aos professores em formação desenvolver conhecimento e competências profissionais que os capacitam, nomeadamente, para uma intervenção pedagógica que assegure um exercício mais democrático da justiça linguística em situações educativas de contacto intercultural. Sintetizando, podemos dizer que a educação para a diversidade linguística se pode definir como uma forma de colocar no currículo diferentes línguas de diferentes estatutos e tipologias, pretendendo

[...] contribuir para políticas e práticas de maior participação e de maior poder, $[\ldots]$ lutar por maior justiça linguística, apostando em dar visibilidade a diferentes vozes e a diferentes objetos linguísticos nos lugares e territórios em que o mundo se organiza e nas dinâmicas comunicativas e educativas que se vão construindo entre os sujeitos desses mesmos territórios e lugares. (ANDRADE; MARTINS; PINHO, 2014, p. 178).

Neste sentido, a educação para a diversidade linguística parece permitir práticas de inovação curricular de caráter transversal, interdisciplinar e global (LEITE; FERNANDES, 2010), potenciando o desenvolvimento profissional daqueles que as concebem, implementam e avaliam.

Vejamos, então, o que acontece quando pretendemos formar professores capazes de dar resposta aos desafios da diversidade que caracteriza cada vez mais os contextos educativos, isto porque "Los profesores reaparecen, en este comienzo del siglo XXI, como elementos insustituibles, no solo en el fomento de los aprendizajes, sino tambien en la construccion de procesos de inclusion 
que respondan a los desafios de la diversidade [...]." (NÓVOA, 2009, p. 49, itálicos do autor).

\section{$O$ contexto do estudo}

Para compreendermos o estudo aqui apresentado importa perceber o contexto em que se produzem os relatórios analisados. Trata-se de textos que concluem um processo formativo de aquisição de habilitação profissional para o exercício da docência no $1^{\circ} \mathrm{CEB}$, o que permite lê-los como balanços de uma experiência passada e como planificadores de desenvolvimentos futuros relativamente à ação educativa. De uma forma geral, podemos dizer que, tal como em outros contextos, entende-se a escrita de relatórios de estágio como um espaço de documentação, análise e reflexão sobre a prática com vista à construção de conhecimento profissional que sustenta essa mesma prática. Crinon e Guige (2006) afirmam que as escritas formativas permitem ao formando exercitar-se na análise dos efeitos da sua ação pedagógica, descrevendo e restituindo experiências concretas de educação, para a diversidade linguística neste caso específico.

Os mestrados em ensino em Portugal incluem áreas de formação como a formação educacional geral, as didáticas específicas, a iniciação à prática profissional, a formação cultural, social e ética e uma componente de investigação educacional. Na Universidade de Aveiro foi desenhado um perfil de formação, o mestrado em Educação Pré-Escolar e Ensino do $1^{\circ}$ CEB $(90$ ECTS $/ 3$ semestres), contemplando estas áreas de formação e relacionando as unidades curriculares (UC) de iniciação à prática profissional e de seminário de investigação educacional, localizadas nos dois últimos semestres do curso. Tendo em conta o perfil profissional e académico dos diferentes docentes que acompanham os estudantes nestas UC, foram constituídas subáreas de investigação educacional (matemática, ciências, língua portuguesa, diversidade linguística e cultural, formação pessoal e social, etc.). A área da diversidade linguística e cultural definiu como finalidades de formação: a construção de conhecimento educacional sobre a introdução da diversidade linguística nos primeiros anos de escolaridade; a conceção, desenvolvimento, avaliação e fundamentação de projetos de intervenção educativa; e a redação de um relatório final, com defesa pública, com reflexão sobre o percurso individual de formação, construído em torno de um projeto de educação para a diversidade linguística e cultural. Como ocorre em outras instituições de formação do país (ver VIEIRA; SILVA; ALMEIDA, 2014, a propósito do estágio da Universidade do Minho), também na Universidade 
de Aveiro se visa promover uma relação estreita entre ensino e investigação, construção de conhecimento na ação e para a ação, conhecimento declarativo (sobre um tema de interesse educacional) e conhecimento processual, orientando os futuros professores para investigarem a sua própria ação, numa perspetiva de transformação dos sujeitos, dos contextos e das práticas. Assim, com a finalidade de procurar compreender o que ganham os futuros professores com o tratamento da diversidade linguística e cultural nas suas práticas educativas e que possibilidades de construção de conhecimento profissional deixa antever a comunicação das experiências, analisaram-se 20 relatórios, relativos a 10 projetos de intervenção educativa desenvolvidos em díade. Os textos foram codificados através da designação $\mathrm{R}$, sucedida de um número, atribuído de acordo com a ordem alfabética do nome da sua autora (ver corpus em anexo). Os relatórios, disponíveis no Repositório Institucional da Universidade de Aveiro ( $<\mathrm{http}: / /$ ria.ua.pt/>), foram lidos na íntegra, com enfoque particular nas palavras-chave, na introdução e conclusões ou considerações finais. Recorreu-se à técnica de análise de conteúdo, tendo-se identificado recortes discursivos indiciadores de construção de conhecimento profissional a partir do tratamento educativo da diversidade linguística em contexto escolar. Foram identificadas as seguintes categorias de análise, relativas a dimensões do conhecimento profissional: a) capacidade de pesquisa de informação sobre a diversidade linguística e cultural como objeto de intervenção educativa em abordagens diversas como a sensibilização à diversidade linguística, a intercompreensão ou o desenvolvimento da competência plurilingue; b) capacidade de articulação da diversidade linguística e cultural com outras áreas do currículo nos primeiros anos de escolaridade; c) capacidade de reflexão sobre as finalidades educativas do tratamento da diversidade linguística; e d) capacidade de reflexão sobre a construção do seu próprio conhecimento profissional, na compreensão do professor como gestor do currículo, comunicador e investigador da sua prática.

\section{Análise e discussão dos resultados}

Os relatórios, com uma extensão aproximada de 100 páginas, são compostos por diferentes capítulos e diversos anexos que apresentam as planificações das autoras, os recursos didáticos utilizados, bem como os instrumentos de recolha de dados e a compilação dos próprios dados recolhidos junto das crianças. Para além de uma introdução e uma secção com referências bibliográficas, os relatórios são, normalmente, compostos por dois ou três capítulos de enquadramento 
conceptual, um capítulo de explicitação metodológica, onde é apresentado o projeto de intervenção, e um capítulo de análise e discussão dos resultados da experiência pedagógico-didática planeada, experimentada e avaliada. Os relatórios terminam, na conclusão ou nas considerações finais, com um balanço do percurso realizado, balanço esse que se constrói em torno das aprendizagens das crianças e/ou das aprendizagens da professora em formação, autora do relatório.

Podemos dizer que os relatórios evidenciam, pela revisão da literatura apresentada, capacidade de fundamentação das intervenções realizadas em contexto educativo real. As futuras professoras revelam capacidade de se informarem sobre diferentes dimensões do seu conhecimento profissional em construção, num conjunto de saberes que explicitam em torno da educação para a diversidade linguística e cultural, saberes esses que são capazes de pesquisar e de articular com outras áreas curriculares. O Quadro 1 apresenta os resultados da análise das dimensões do conhecimento profissional presentes nos relatórios e a distribuição dos respetivos recortes discursivos.

\section{QUADRO 1 - DIMENSÕES DO CONHECIMENTO PROFISSIONAL NOS RELATÓRIOS DE ESTÁGIO}

\begin{tabular}{|c|c|c|c|}
\hline $\begin{array}{l}\text { Dimensões do conhecimento } \\
\text { profissional }\end{array}$ & Temas dos relatórios & Relatórios & $\begin{array}{l}\text { Recortes } \\
\text { discursivos }\end{array}$ \\
\hline \multirow{4}{*}{$\begin{array}{l}\text { a) diversidade linguística e } \\
\text { abordagens educativas }\end{array}$} & $\begin{array}{l}\text { sensibilização à diversidade } \\
\text { linguística }\end{array}$ & $\begin{array}{l}\text { R1, R2, R4, R7, R8, R9, } \\
\text { R13, R14, R16, R17, } \\
\text { R18, R19 }\end{array}$ & 12 \\
\hline & intercompreensão & $\begin{array}{l}\text { R3, R5, R6, R7, R10, } \\
\text { R12, R15, R17, R20 }\end{array}$ & 9 \\
\hline & $\begin{array}{l}\text { plurilinguismo/competência } \\
\text { plurilingue }\end{array}$ & $\begin{array}{l}\text { R3, R6, R7, R12, R17, } \\
\text { R20 }\end{array}$ & 6 \\
\hline & & Total de recortes & 27 \\
\hline \multirow{3}{*}{ b) articulação curricular } & língua portuguesa & $\begin{array}{l}\text { R1, R2, R3, R4, R6, R8, } \\
\text { R9, R11, R12, R13, R16, } \\
\text { R20 }\end{array}$ & 12 \\
\hline & estudo do meio & R3, R5, R12, R14, R15 & 5 \\
\hline & & Total de recortes & 17 \\
\hline \multirow{4}{*}{$\begin{array}{l}\text { c) finalidades educativas e } \\
\text { diversidade linguística }\end{array}$} & $\begin{array}{l}\text { direitos (linguísticos, } \\
\text { culturais, da criança) }\end{array}$ & $\mathrm{R} 8$ & 1 \\
\hline & desenvolvimento sustentável & R14, R17 & 2 \\
\hline & educação para a cidadania & R17, R19 & 2 \\
\hline & & Total de recortes & 4 \\
\hline \multirow{4}{*}{$\begin{array}{l}\text { d) desenvolvimento } \\
\text { profissional do professor em } \\
\text { formação }\end{array}$} & gestor do currículo & $\mathrm{R} 3, \mathrm{R} 4, \mathrm{R} 8, \mathrm{R} 15$ & 4 \\
\hline & comunicador & R5, R7, R10 & 3 \\
\hline & investigador da sua prática & $\mathrm{R} 11, \mathrm{R} 12$ & 2 \\
\hline & & Total de recortes & 9 \\
\hline
\end{tabular}

FONTE: As autoras (2016). 
Analisando o quadro, podemos observar, como expectável, que a diversidade linguística, à exceção de R11, atravessa os relatórios, revelando um certo consenso discursivo em torno do percurso de formação centrado sobre uma investigação-ação em contexto escolar onde são experimentadas e avaliadas atividades de educação para a diversidade linguística e cultural. Neste sentido, as professoras em formação parecem reconhecer esta área como potenciadora de aprendizagens profissionais várias, revelando preocupação em construir conhecimento sobre as suas práticas pedagógico-didáticas, como mostram os 27 recortes discursivos dos relatórios analisados (12 recortes sobre a sensibilização à diversidade linguística, 9 sobre a intercompreensão e 6 sobre o desenvolvimento da competência plurilingue).

As professoras em formação desenvolvem ainda o seu conhecimento profissional pela capacidade de gerirem o currículo, articulando a diversidade linguística com o tratamento de conteúdos previstos nos programas oficiais de língua portuguesa ( 12 recortes), nos domínios da leitura e da compreensão leitora, da escrita, da educação literária e da gramática, bem como nos programas do estudo do meio (5 recortes). Assim, encontramos, por exemplo, capítulos de informação sobre o ensino da língua portuguesa, onde são aprofundados os géneros textuais (poesia, conto e texto expositivo), a gramática e o desenvolvimento da consciência linguística, metalinguística e/ou grafofonológica. Encontramos na área de estudo do meio capítulos relacionados com o conhecimento do mundo na área das ciências naturais e/ou sociais.

Apesar do menor número de recortes discursivos relativos ao desenvolvimento da capacidade de reflexão sobre o seu próprio desenvolvimento profissional (9 no total), eles mostram que o professor é um sujeito que tem de saber gerir o currículo, saber comunicar e ter conhecimento sobre o mundo das línguas e das culturas, incluindo uma capacidade de análise dessas mesmas línguas e culturas em diferentes situações, bem como compreender os benefícios da investigação para a ressignificação da sua própria prática. Como escrevem duas das futuras professoras, "importa refletir um pouco sobre as línguas que foram abordadas nas sessões” (R7, p. 127) ou "Este estudo foi bastante importante e positivo para nós, uma vez que este projeto nos proporcionou contactar com outras línguas, que conhecemos só de ouvir falar, como a língua romena ou a língua catalã, desenvolvendo nós próprias capacidades de compreensão leitora." (R10, p. 121). Podemos dizer que os projetos apresentados e relatados pelas professoras em formação seguem todos uma metodologia com características de investigação-ação e permitem compreender como se pode promover uma educação para a diversidade linguística e cultural, gerindo o currículo oficialmente previsto. $\mathrm{O}$ processo de investigação, com análise e interpretação de dados recolhidos junto dos alunos do $1^{\circ} \mathrm{CEB}$, permite às futuras professoras 
compreender a importância das experiências pedagógico-didáticas realizadas. No entanto, só 4 recortes discursivos nos permitem dizer que existe uma clara compreensão das finalidades educativas das práticas de educação para a diversidade linguística e cultural:

O presente trabalho marca o culminar de um trajeto formativo integrado [...]. As etapas deste percurso exigiram que a investigação e a reflexão estivessem sempre presentes, para auxiliar a compreensão da ação educativa e do contexto educativo na sua complexidade e diversidade, mas também para pensar em possibilidades de intervenção educativa e refletir sobre o processo de ensino e aprendizagem dos alunos [...] Através da investigação, foi-nos possível construir conhecimento teórico sobre intercompreensão [...]. (R3, p. 107).

As futuras professoras percebem a importância da formação que realizaram, tomando consciência da complexidade do conhecimento profissional e da dificuldade em aprenderem a ser professoras. Como escreve Caena (2014), tomando consciência da complexidade do ato de ensinar, os professores em formação constroem disposições para aprender, desaprender e reaprender, ajustando-se às especificidades das situações que têm de gerir e às necessidades dos sujeitos com quem interagem. As futuras professoras parecem compreender os desafios da profissão docente, percebendo a importância dos diferentes conhecimentos, etapas e atividades que conduzem à redação e comunicação da experiência realizada, onde a ação pedagógico-didática se torna o espaço crucial de construção de conhecimento profissional, como confirma a literatura da especialidade. $\mathrm{O}$ discurso que produzem aponta para um processo em que dizem ter aprendido bastante, com sucessos, mas também com muitas dificuldades:

Após um longo caminho percorrido, este produto final é resultado de um percurso marcado por anseios, medos e dificuldades, mas também por aprendizagens, alegrias e vitórias no que respeita ao estágio desenvolvido e, por conseguinte, ao projeto de intervenção-investigação implementado [...]. A caminhada efetuada até aqui foi marcada por uma grande pesquisa e instrução a nivel teórico, por semanas de estágio onde a implementação do projeto se revelou o ponto crucial e por um período de análise com o objetivo de perceber que resultados se conseguiram obter. Tudo isto possibilitou o desenvolvimento de aprendizagens por parte dos alunos e da professora estagiária, autora deste relatório. (R8, p. 155). 
Encontramos nas conclusões dos relatórios uma valorização das atividades dos projetos de investigação-ação, bem como dos processos de colaboração e de comunicação que permitiram realizar esses projetos e relatá-los:

Para além do contributo global que este projeto teve para os participantes envolvidos, também para mim, como investigadora, como futura profissional de educação e como pessoa, este estudo se revelou como um momento marcante ao longo da minha vida. No que diz respeito à minha formação académica, foi-me proporcionada a oportunidade de aplicar os conhecimentos adquiridos até então [...]. Como futura profissional, considero que este projeto foi uma mais-valia, uma vez que desenvolvi a minha capacidade de planear, observar, de agir e de refletir acerca da minha ação [...] além disso, desenvolvi também a capacidade de trabalhar em conjunto, colaborando com os outros, partilhando ideias, tornando-as práticas. Ao nivel pessoal, posso dizer que cresci e me sinto melhor com o meu novo "eu". Tornei-me mais aberta às diferenças, à diversidade, à interação e comunicação com o Outro. (R4, p. 93-94).

Podemos dizer que os textos que concluem os relatórios de estágio analisados deixam perceber conhecimento construído sobre a dimensão da investigação no tornar-se professor, traduzida numa compreensão da importância da aprendizagem constante, em diferentes modalidades e sobre múltiplos objetos, revisitando percursos efetuados e abrindo intenções futuras de formação. Como escreve uma estudante: "Resta-nos regozijarmo-nos pela superação deste enorme desafio, almejando ter oportunidade de repetirmos (com melhorias) as estratégias/atividades experimentadas com este projeto e de desenvolvermos novos projetos que nos possibilitem atingir novos objetivos.” (R12, p. 136). Nesta linha, as professoras em formação referem-se ao seu conhecimento profissional em construção, que abrange conhecimento declarativo sobre teorias educativas e se estende à capacidade de aplicar esse conhecimento em situações educativas concretas, deixando perceber um pensamento estratégico para tratar a diversidade linguística no currículo escolar que (re)constroem.

Os relatórios de estágio constituem-se assim como textos que descrevem práticas que as futuras professoras desenvolveram e organizam no final do processo, no discurso profissional que conseguem produzir, dando-lhes sentido e deixando entrever modos de atuação futura, onde a questão da diversidade é considerada, tal como se pode ler no recorte seguinte: 
[...] para concluir, espero que, com este trabalho que desenvolvi, possa ter incentivado o desenvolvimento de práticas de educação para a diversidade linguística e cultural e para os direitos humanos. Espero que estas duas grandes temáticas se tenham tornado mais significativas para os alunos e para a comunidade escolar, passando a mensagem de que a sua aprendizagem é tão importante como o português ou a matemática. Espero ter mudado um pouco o mundo dos alunos, de forma a que eles perspetivem a escola e a comunidade como contextos de inclusão, estabelecendo uma convivência democrática e participada, conscientes dos seus direitos e deveres. (R8, p. 162).

De um modo geral podemos dizer que os relatórios analisados indiciam, por parte das professoras em formação, um processo de construção da profissão, mais ou menos observado, descrito, refletido e restituído na escrita que apresentam para avaliação do seu conhecimento profissional. No entanto, só algumas parecem compreender verdadeiramente o alcance das atividades que desenvolvem quer em termos das suas finalidades educativas, quer em termos do seu próprio desenvolvimento profissional, sempre personalizado e único.

\section{Considerações finais}

A análise dos relatórios de estágio das futuras professoras do $1^{\circ} \mathrm{CEB}$ revela, em termos gerais, que as autoras aproveitaram a escrita do relatório para observarem e analisarem o seu percurso de formação profissional, distanciando-se das práticas que colocaram em ação, procurando agora inseri-las em trajetórias mais globais de desenvolvimento profissional e sendo capazes de descrever o que foram capazes de realizar e de aprender, mesmo se nem todas indiciam capacidade de problematização e de reflexão crítica sobre a experiência formativa vivenciada.

Os relatórios de estágio ou de final de curso revelam que a escrita do relatório se constituiu como um espaço de compreensão e de restituição de um percurso formativo realizado, evidenciando dimensões importantes do conhecimento profissional construído e a construir, onde atividades de informação como a leitura e a análise das experiências pedagógico-didáticas, o diálogo com os outros e a reflexão sobre o currículo e os resultados das experiências levadas a cabo são retomados para fecho de um processo que se pensa continuar a desenvolver. 
Inserido num projeto mais vasto de análise da construção profissional na formação inicial, o estudo aqui apresentado aponta para a necessidade de continuarmos a interrogar-nos sobre o que podem significar os relatórios de estágio como lugares de construção de uma profissão e de que forma o tratamento da diversidade linguística permite aos profissionais de educação encontrarem um lugar na multiplicidade de discursos que os rodeiam e lhes são, muitas vezes, impostos, construindo uma identidade profissional própria. $\mathrm{O}$ estudo mostra-nos que as professoras em formação, num mestrado profissionalizante, compreendem, na construção do seu relatório de estágio, a complexidade da profissão, iniciando um processo de gestão da complexidade dos aspetos a ter conta na aprendizagem docente: os tópicos ou conteúdos a dominar; as abordagens pedagógico-didáticas que podem utilizar; o currículo, os programas oficiais e suas finalidades educativas; os alunos e o seu próprio conhecimento em construção. Como dissemos, algumas professoras em formação percebem que a área da educação para a diversidade linguística e cultural se constitui como mobilizadora do seu conhecimento profissional em construção, permitindo gerir o currículo de modo transversal e inovador pelas exigências que coloca na conceção e atualização das práticas educativas e na compreensão das finalidades educativas.

$\mathrm{O}$ estudo apresentado sobre relatórios de estágio no quadro da educação para a diversidade linguística e cultural mostra que esta é uma temática mobilizadora na construção de conhecimento profissional docente pela sua transversalidade e caráter inovador, permitindo uma compreensão do currículo e da profissão, necessitando de um investimento em estratégias de formação que potenciem a articulação entre as diferentes dimensões do conhecimento profissional. Para tal, importa investir em redes de investigação que analisem as potencialidades formativas dos cursos de mestrado profissionalizantes, com incidência no processo de formação que condiciona e conduz ao relatório final de estágio, construindo conhecimento sobre este tipo de textos, sobre a sua especificidade, sobre os tópicos que os organizam, sobre a sua função na formação, bem como sobre os modos de acompanhar esse processo.

\section{REFERÊNCIAS}

ANDRADE, A. I.; MARTINS, F.; PINHO, A. S. Abordar as línguas nos primeiros anos de escolaridade: que possibilidades de educação para a valorização da diversidade linguística. In: MOREIRA, M. A.; ZEICHNER, K. (Org.). Filhos de um Deus Menor: 
diversidade linguística e justiça social na formação de professores. Ramada: Edições Pedago, 2014. p. 175-192.

AVALOS, B. Los conocimientos y las competencias que subyacen a la tarea docente. In: VÉLAZ DE MEDRANO, C. Y.; VAILLANT, D. (Org.). Aprendizaje y desarrollo profesional docente. Madrid: OEI, 2009. p. 67-77.

CAENA, R. Initial teacher education in Europe: an overview of policy issues. European Commission. ET2020 Working Group on Schools Policy, 2014.

CANDELIER, C.; CAMILLERI-GRIMA, A.; CASTELLOTTI, V.; DE PIETRO, J.-F.; LÖRINCZ, I.; MEIßNER, F.-J.; NOGUEROL, A.; SCHRÖDER-SURA, A. (Coord.). Framework of reference for pluralistic approaches to languages and cultures. Graz: ECML, 2007. Disponível em: <http://carap.ecml.at/Portals/11/documents/C4pub2007E_20080302_FINAL.pdf>. Acesso em: 14 set. 2016.

CLARKE, M.; LODGE, A.; SHEVLIN, M. Evaluating initial teacher education programmes: perspectives from the Republic of Ireland. Teaching and Teacher Education, v. 28, p. 141-143, 2012.

CRINON, J.; GUIGUE, M. Écriture et professionnalisation. Revue française de pédagogie, v. 156, p. 117-169, 2006.

FLORES, M. A. Algumas reflexões em torno da formação inicial de professores. $E d u$ cação, v. 33, n. 3, p. 182-188, 2010.

FLORES, M. A. Curriculum of initial teacher education in Portugal: new contexts, old problems. Journal of Education for Teaching, v. 37, n. 4, p. 461-470, 2011.

FLOYD, D. M.; COLVIN, G.; BODUR, Y. A faculty-librarian collaboration for developing information literacy skills among pre-service teachers. Teaching and Teacher Education, v. 24, p. 368-376, 2008.

GOMES, S. Diversidade linguística e desenvolvimento profissional de professores: um estudo no $1^{\circ}$ ciclo do ensino básico. Tese (Doutorado) - Universidade de Aveiro, Aveiro, 2013. Disponível em: <http://ria.ua.pt/handle/10773/11484> . Acesso em: 14 set. 2016.

LEITE, C.; FERNANDES, P. Desafios aos professores na construção de mudanças educacionais e curriculares: que possibilidades e que constrangimentos? Educação, v. 33, n. 3, p. 198-204, 2010.

LOMBARDI, G.; DE VOLLMER, A. La formación docente como sistema: de la formación inicial al desarrollo profesional. Reflexiones a partir de la experiencia argentina. In: VÉLAZ DE MEDRANO, C.; VAILLANT, D. (Org.). Aprendizaje y desarrollo profesional docente. Madrid: Organización de Estados Iberoamericanos para la Educación, la Ciencia y la Cultura (OEI), 2009. p. 59-66.

LOURENÇO, M. Educação para a diversidade e desenvolvimento fonológico na infância. Tese (Doutorado) - Universidade de Aveiro, Aveiro, 2013. Disponível em: $<$ http://ria. ua.pt/handle/10773/11428>. Acesso em: 14 set. 2016. 
LOURENÇO, M.; ANDRADE, A. I. Promoting phonological awareness in pre-primary education: possibilities of the "awakening to languages" approach. Language Awareness, v. 23, n. 4, p. 304-318, 2014. Disponível em: <http://dx.doi.org/10.1080/09658416.201 3.783585>. Acesso em: 14 set. 2016.

MARCELO, C. Desenvolvimento profissional docente: passado e futuro. Sísifo. Revista de Ciências da Educação, v. 8, p. 7-22, 2009.

MORAN, M. J. Collaborative action research and project work: promising practices for developing collaborative inquiry among early childhood pre-service teachers. Teaching and Teacher Education, v. 23, p. 418-431, 2007.

MULE, L. Preservice teachers' inquiry in a professional development school context: Implications for the practicum. Teaching and Teacher Education, v. 22, p. 205-218, 2006.

NÓVOA, A. Profesores: ¿el futuro aún tardará mucho tiempo? In: VÉLAZ DE MEDRAN, C.; VAILLANT, D. (Org.). Aprendizaje y desarrollo profesional docente. Madrid: OEI. Fundación Santillana, 2009. p. 49-56.

PARKER, D. C. Writing and becoming [a teacher]: Teacher candidates' literacy narratives over four years. Teaching and Teacher Education, v. 26, p. 1249-1260, 2010.

RIOS, T. Comprender y enseñar. Por una docência de la mejor calidad. Barcelona: Graó, 2010.

SÁ-CHAVES, I. A construção de conhecimento pela análise reflexiva da praxis. Lisboa: Fundação Calouste Gulbenkian - Fundação para a Ciência e a Tecnologia, 2002.

SCHERFF, L.; SINGER, N. R. The preservice teachers are watching: framing and reframing the field experience. Teaching and Teacher Education, v. 28, p. 263-272, 2012.

SCHLEICHER, A. (Ed.). Preparing teachers and developing school leaders for the 21st century: lessons from around the world. OECD Publishing, 2012.

SUMSION, J.; PATTERSON, C. The emergence of community in a pre-service teacher education program. Teaching and Teacher Education, v. 20, p. 621-635, 2004.

TOWNSEND, T. Searching high and searching low, searching east and searching west: looking for trust in teacher education. Journal of Education for Teaching, v. 37, n. 4, p. 483-499, 2011.

VIEIRA, F.; MOREIRA, M. A. Supervisão e avaliação do desempenho docente. Lisboa: Conselho Coordenador para a Avaliação de Professores, 2011.

VIEIRA, F.; MOREIRA, M. A.; PERALTA, H. Research in foreign language education in Portugal (2006-2011): its transformative potential. Language Teaching, v. 47, p. 191-227, 2014.

VIEIRA, F.; SILVA, J. L.; ALMEIDA, M. J. Estudar o que fazemos, fazer o que estudamos: a investigação a serviço da formação e do desenvolvimento profissional dos 
formadores. In: CONGRESO IBEROAMERICANO DE DOCÊNCIA UNIVERSITARIA E DE NÍVEL SUPERIOR, VIII., 2014, Rosário. Atas... Rosário, 2014.

Texto recebido em 03 de outubro de 2016. Texto aprovado em 04 de novembro de 2016.

\section{Anexo - Corpus do estudo}

(Disponível em: <http://ria.ua.pt>)

R1/Castro, A (2014). Ensino da poesia e diversidade linguística: um estudo no $2^{\circ}$ ano de escolaridade.

R2/Duarte, S. (2014). Diversidade linguística e consciência metalinguística.

R3/Fernandes, M. (2013). Intercompreensão, gestão do currículo e competência metalinguística.

R4/Fonseca, S. (2014). Diversidade linguística no ensino da flexão nominal em número no $1^{\circ} \mathrm{CEB}$.

R5/Gomes, C. (2015). Intercompreensão na abordagem de conteúdos da área de Estudo do Meio.

R6/Gomes, C. S (2013). Intercompreensão e poesia no $1^{\circ}$ CEB - os sons das línguas.

R7/Machado, C. (2012). Plurilinguismo e línguas românicas: estudo no $3^{\circ}$ ano de escolaridade.

R8/Maia, C. (2015). O direito à educação para a diversidade linguística e cultural.

R9/Moreira, S. (2012). Escrever textos poéticos e sensibilizar à diversidade linguística.

R10/Neto, M. (2012). Línguas românicas e intercompreensão no $3^{\circ}$ ano de escolaridade.

R11/Oliveira, C. (2012). Escrever contos, conhecer o mundo.

R12/Paula, J. (2015). Intercompreensão em línguas românicas - uma abordagem do texto expositivo no $1^{\circ} \mathrm{CEB}$.

R13/Pereira, S. (2014). Diversidade linguística no ensino da flexão nominal em género no $1^{\circ} C E B$.

R14/Ribas, C. (2014). O desenvolvimento sustentável e a língua portuguesa no $1^{\circ} \mathrm{CEB}$.

R15/Ribeiro, A. C. (2013). Intercompreensão, plurilinguismo como valor e gestão do currículo.

R16/Rijo, C. (2012). Abordar as línguas, desenvolver a competência linguística. 
R17/Santos, M. (2014). As línguas na educação para o desenvolvimento sustentável no $1^{\circ} \mathrm{CEB}$.

R18/Sousa, I. (2012). Cultura linguística e sensibilização à diversidade linguística - $1^{\circ}$ CEB.

R19/Sousa, M. (2015). Cidadania e educação intercultural: um estudo no $1^{\circ}$ Ciclo do Ensino Básico.

R20/Vasconcelos, A. C. (2013). Intercompreensão e poesia: promoção da competência lexical e semântica. 